\title{
9. Designing for Persuasion through Embodied Experiences in Virtual Reality
}

\author{
Sun Joo Ahn
}

\begin{abstract}
Embodied experiences in virtual reality (VR) involves the reproduction of sufficiently realistic sensory information so that users are able to see, hear, and feel experiences as if they are going through them at the moment. A growing body of literature evinces that the effects of these virtual experiences carry over into the physical world to impact attitudes and behaviors in the physical world. Underlying mechanisms of embodied experiences that produce these outcomes are discussed in the context of media affordances or interactions between novel attributes of VR and user perceptions of them. Design implications to maximize persuasive effects are examined and illustrated with case studies. Finally, the limitations of embodied experiences are considered using the efficiency framework.
\end{abstract}

Keywords: virtual reality; embodied experiences; media affordances; persuasive effects

\section{Introduction}

Immersive virtual environments are digitally rendered spaces offering sensory-rich simulations that allow users to experience mediated events in the virtual world as they might in the physical world (Blascovich \& Bailenson, 2011). Commonly referred to as virtual reality (VR), these highly immersive systems use digital devices to deliver embodied experiences - the reproduction of sufficiently realistic sensory information so that users are able to see, hear, and feel experiences as if they are going through them

Hera, T. Dela, J. Jansz, J. Raessens, B. Schouten, Persuasive Gaming in Context. Amsterdam: Amsterdam University Press, 2021 DOI 10.5117/9789463728805_CHO9 
at that moment (Ahn, Bailenson, \& Park, 2014). The concept of VR is not new - in fact, the discussion and scholarship of virtual environments has a decades-long history (Lanier \& Biocca, 1992; Rheingold, 1992; Sutherland, 1968). However, the costs associated with VR were prohibitive in its earlier years, confining the technology to sophisticated research laboratories and high-tech facilities. With a number of large corporations developing proprietary devices for VR systems, consumers are now able to purchase VR devices at common retail or electronic stores at an affordable price point. Now that VR has the potential to become a ubiquitous, everyday technology, discussions on how VR experiences may alter and transform users' ways of thinking and behaving are timely and imperative.

\section{Using embodied experiences to impact attitudes and behaviors}

Embodied experiences in VR are uniquely positioned to impact attitudes and behaviors because of their ability to mimic direct experiences in physical worlds by providing users with a broad spectrum of simulated information. A growing body of literature demonstrates that embodying visceral experiences in virtual worlds can shift the way people think, feel, and behave, and that these effects persist and transfer into the physical world to influence attitudes and behaviors over time, after people have left the virtual worlds (Ahn, 2015; Ahn, Fox, Dale, \& Avant, 2015; Ahn, Bailenson, \& Le, 2013). A deeper understanding of why and how embodied experiences can impact users will yield opportunities to harness the persuasive powers of virtual worlds to promote desirable behaviors.

\section{The persuasive power of direct experiences}

Much of the excitement surrounding VR involves how realistically the mediated environment is able to deliver experiences 'just like' the physical world. Articles from both the academic and popular press often compare VR to traditional media platforms such as television or books and note the technology's ability to put users in simulations that make them seem as if they are really ducking bullets in a war zone, swimming with marine life in the sea, or exploring crevices on Mars. Why are people so interested in creating authentic and realistic experiences in VR, and how do these impact users?

Social scientists have noted for decades that direct experiences, wherein the person has first-hand contact with the event, seem to have meaningful 
effects on attitudes and behavior change compared to indirect experiences, wherein the person has secondhand contact with the event. As direct and indirect experiences are encountered in different formats, they are encoded in the mind differently and therefore affect attitudes and behaviors in different ways (Hamilton \& Thompson, 2007). As a result, individuals form stronger attitudes, feel more confident about the attitudes formed, and ultimately behave more consistently with those attitudes from direct than indirect experiences (Fazio \& Zanna, 1991; Wu \& Shaffer, 1987). Due to this confidence in the attitudes formed, individuals place greater weight on direct than indirect experiences when making decisions; personal experience of an event makes the information more salient and serves as a more significant point of reference than a description of the event (Hertwing et al., 2004; Rajecki, 1982). These findings suggest that, when designing for persuasion, experiences that closely mimic first-hand events may be more effective than secondhand depictions.

Direct experiences provide rich raw materials for constructing mental schemata that are to be later activated and recalled when individuals encounter or think about similar stimuli (Barsalou, 2009). This implies that, given sufficient perceived realism and authenticity, embodied experiences in VR may continue to influence attitudes and behaviors outside the virtual world when individuals encounter similar stimuli in the physical world. So, designing for persuasion in VR involves the consideration of sustained effects that last over time, which might be a more cost-effective approach to persuasion than using traditional media, which yields effects that dissipate relatively faster (Ahn, 2015; Ahn et al., 2014). The ability of embodied experiences to mimic direct experiences in the physical world becomes even more meaningful when taking into consideration VR's capacity to deliver experiences that are difficult or impossible to encounter in the physical world. For these events, embodied experiences in VR provide a useful platform to persuade people to consider risks or future negative consequences that would be difficult to communicate otherwise.

\section{Mechanisms of persuasion through embodied experiences: an affordance-based approach}

VR offers a wide range of features that distinguish the platform from traditional channels. However, features alone, without considering user perceptions and preferences, may not be enough to persuade. Consider, for instance, digital devices with features that are not well understood and are 
therefore rarely used by individuals: Although the feature exists, if the user doesn't take advantage of it, it fails to affect the user in any way. On the other hand, the potential for using devices in a certain way wouldn't exist at all without the features themselves. As such, exploring the 'relational structure' of affordances - the dynamic interaction between users and features mutually deciding the capabilities and limitations of technologies-is critical (Evans, Pearce, Vitak, \& Treem, 2017). How do these affordances promote or hinder persuasive outcomes through embodied experiences?

\section{Presence}

When VR uses digital devices to produce realistic sensory information, users may temporarily forget that they are in a mediated world and feel as if they have genuinely visited a different space (Lombard \& Ditton, 1997; Slater \& Wilbur, 1997). This feeling of 'being there' in the virtual world during an embodied experience is referred to as presence (Biocca, 1997). Although presence is often discussed in the context of VR, the ability of users to feel present in a believable illusion of mediated environments can be applied to other platforms as well, including video games (Tamborini \& Skalski, 2006), television (Kim \& Biocca, 1997), and books (Schubert \& Crusius, 2002).

Presence is applicable across different platforms because this affordance is the result of dynamic interactions between the modality features that support the delivery of sensory information and users' psychological willingness to mentally construct a believable illusion of authentic experiences (Lee, 2004). Conceptually, media features alone are insufficient to induce feelings of presence. So, Eva might feel that she was really walking on the surface of Mars in a virtual simulation, but Teresa might feel that the same simulation of Mars was not sufficiently realistic and will still feel physically situated in her own living room.

However, the reason that the concept of presence is commonly discussed in the context of VR is because its features facilitate the delivery of multiple layers of sensory information that envelop the user without him/her having to actively engage in mental imagery. By surrounding the user with multiple cues, such as visual, aural, and tactile information, VR may serve as the facilitator of presence, given equal individual capacity and the motivation to perceive presence. This is why the bulk of scholarly work on VR associates greater levels of perceived presence with higher levels of interactivity, richness, and immersion. As a consequence, more technologically sophisticated virtual environments are more conducive to higher perceptions of presence than virtual environments that provide fewer perceptual cues. 
Particularly relevant to embodied experiences is the dimension of spatial presence, which refers to the extent to which the user feels that the objects and events encountered in the mediated environment are authentic (Lee, 2004; Lombard \& Ditton, 1997). There are several measures that assess the perception of spatial presence (Schubert, Friedmann, \& Regenbrecht, 2001; Witmer \& Singer, 1998). Commonly used items gauge the extent to which users feel that they can reach out to touch and move objects in the mediated space (possible actions), or the extent to which they feel as if they are surrounded by their environment (self-location), which illustrates the focal points of the construct (Wirth et al., 2007). The bulk of the scholarship around spatial presence has focused on visual and aural cues, perhaps because these are the dominant sense modalities and are what drive our perceptions and understanding of the world that surrounds us. With the development of haptic controllers, studies of tactile cues are on the rise, but the roles of tactile, olfactory, and gustatory cues in the construction of spatial presence remain largely underexplored.

As the development of virtual worlds has historically been spearheaded by video game industries, discussions of spatial presence in virtual worlds have focused on the domains of user engagement or the enjoyment of the mediated content (Skalski, Tamborini, Shelton, Buncher, \& Lindmark, 2011; Vorderer, Klimmt \& Ritterfeld, 2004). However, features that construct embodied experiences with a high spatial presence go above and beyond mere entertainment, impacting user attitudes and behaviors in the physical world for some time after the virtual experience. If direct physical experiences wield greater influence for attitude and behavior change, virtual simulations that elicit a high spatial presence are able to more closely mimic first-hand experiences and may consequently serve as a more powerful tool of persuasion than media channels that provoke a relatively passive reception from users (Ahn et al., 2015; Kim \& Biocca, 1997; Lombard \& Snyder-Duch, 2001).

\section{Acceleration of time}

In the physical world, time is a structured and continued progression, forever ticking forward at a strict, predetermined pace. In the virtual world, time becomes more fluid. VR facilitates the ability to depict an accelerated progression of time that moves either forward or backward with the help of computer graphics and devices that replicate sensory information. VR can be used to depict incremental levels of change dynamically in a matter of 
minutes, allowing users to embody the changes over time in a way that's impossible in the physical world. For example, environmental damage happens over such an extended period of time that individuals rarely have the opportunity to experience the future negative outcomes of their present behaviors. In VR, however, users may see, hear, and feel the grave dangers of environmental damage in just minutes: experiencing deforestation taking place before their eyes (Ahn et al., 2014) or watching marine animals die as a result of an acidifying ocean (Ahn et al., 2016).

This affordance enables virtual simulations to be more potent and effective tools of persuasion than traditional media platforms. People often underestimate or overestimate the impact of future experiences, thinking of the future as an isolated event, independent of the past and present, and basing their forecasts of the future on successful plans and scenarios rather than on accurate past results (Kahneman \& Lovallo, 1993). Individuals are also likely to have an unrealistic level of optimism in conceptualizing distant future events (Weinstein, 1980). By portraying accelerated depictions of events dynamically, VR provides a means to concretely connect the past, present, and future so that causal relationships become lucid. When it becomes clear that present choices and behaviors lead to negative future consequences, it becomes easier to persuade individuals to change their present behaviors to avoid the virtually experienced negative consequences in the future because the accelerated time in the simulation is likely to elicit a sense of urgency.

\section{Shared experiences through perspective-taking}

Another unique affordance of embodied experiences in VR is the ability to share sensory-rich experiences from a first-person viewpoint. This provides the user with the opportunity to take the perspective of another entity (human or non-human), to see, hear, and feel as it would. Perspective-taking is the mental simulation of a situation that involves placing oneself in the shoes of another via imagination (Batson et al., 1997). In the physical world, perspective-taking is a cognitively effortful task, requiring individuals to invest substantial cognitive resources as they attempt to situate themselves in the position of another being. VR assists in reducing the burden of effort by surrounding the user with layers of sensory information from the perspective of the other entity. So, individuals may see the world through the eyes of a visually impaired person to gain first-hand experience of living with a disability. The affordance of shared experiences through 
perspective-taking may engender higher levels of attitude and behavior change because experiencing an event first-hand leads to high involvement, and involvement often serves as a predictor of persuasion (Petty \& Cacioppo, 1981). Empirical evidence supports this supposition: People who experienced the virtual simulation of living with a visual impairment (e.g., red-green color blindness) actively helped those with disabilities for twice as long as those who were asked to just imagine what it would be like to live with a disability (Ahn et al., 2013). The results also suggested that VR simulation might be more helpful for some than others, depending on individual differences in the motivation for engaging in perspective-taking.

\section{Case studies of persuading through embodied experiences: design applications}

Design elements may be leveraged in VR to heighten the impact of these affordances on persuasion. As embodied experiences differ in nature from traditional practices of media consumption, understanding how these affordances can be translated into design applications in VR is critical. Some case studies that illustrate how these designs may be integrated into the development of the virtual simulation for attitude and behavior change are presented next.

\section{Communicating risk}

Risk is defined as 'things, forces, or circumstances that pose danger to people or to what they value' (Stern \& Fineberg, 1996). The anticipation of, and the desire to avoid, negative consequences as a result of the risk event motivates behavior change for self-protection reasons (O'Connor, Yarnal, Dow, Jocoy, \& Carbone, 2005). Several challenges to risk communication pose difficulties in motivating individuals to change their present behaviors to avoid future negative consequences: People tend to underestimate the influence of situational variables at the time of prediction (Loewenstein, 1996). For example, someone might overestimate his/her will power when it comes to reducing their soft drink consumption immediately following exposure to information on the negative health consequences of sugarsweetened beverages, with the will power subsiding significantly when he/she comes across a vending machine on a hot day. Another challenge of risk communication is that the general public often fails to recognize 
issues when they are not directly or immediately observable. So, although ocean acidification reduces the $\mathrm{pH}$ of the earth's oceans and leads to a grave disruption of the entire marine system, individuals perceive the risk of this disruption to be low because they rarely have the opportunity to see personally the consequences of ocean acidification on marine life.

VR simulations can present changes concretely between the present and the future in mere minutes, and this virtual acceleration of time can help bridge psychological distances between present behaviors and future consequences (Ahn, 2015). The design implementation of accelerating time can involve a variety of techniques. One way to indicate the passing of time is to display a means to tell time, such as a calendar, clock, or the rising and setting of the sun, depicting the rapid progression of time through these objects. So, avatars that instantly and dynamically gain weight as a result of poor dietary choices have been used in virtual simulations to depict future negative health consequences - the moment a user makes an unhealthy food choice in the virtual world, the avatar can be designed to display noticeable changes in body shape and general health (Ahn, 2015; Fox, Bailenson, \& Binney, 2009).

Another way to visualize the acceleration of time is to set 'start' and 'end' points with a virtual human's face and demonstrate how it dynamically transitions from one point to another, for instance, by way of an aging face. FaceApp, a recently launched smartphone application, allows users to easily experience what their face might look like 30 years in the future by taking a selfie and using slider bars to 'age' the face.

Yet another design strategy to demonstrate the acceleration of time is to depict how the environment shifts over time-a dynamic, fast-forwarded rendering of change. So, in a simulation of ocean acidification, participants begin the virtual experience in a clear, underwater world with fish and other marine animals. In a matter of minutes, due to environmental pollution, the participants vividly experienced the marine animals dying and their own avatar bodies disintegrating in a rapidly acidifying body of water (Ahn et al., 2016).

Other design elements can heighten the perception of presence to engender risk perceptions effectively. Although direct experiences are more effective than indirect experiences in encouraging people to become involved with a risk issue, in most cases it would be illogical or even fatal to suggest that people should gain first-hand experience with the risk issue: Imagine suggesting that someone experience cancer or an earthquake. To simulate first-hand experiences of risk events, first-person perspectives that give users the viewpoint of the protagonist are often adopted. So, 
AccuWeather, a weather information provider, has designed a 360-degree video application that places users at the center of extreme weather events, such as tornados or thunderstorms. Allowing users to see, hear, and feel multiple elements of the simulation is likely to increase their perceptions of presence, leading to greater engagement and involvement with the risk issue at hand.

\section{Promoting behaviors}

Social science research has demonstrated that exposure to information alone does not change behavior; instead, personal experiences of prior success are one of the strongest drivers of behavior change (Bandura, 1977). In addition, studies have confirmed intrinsic ties between bodily actions and cognitive processes (Feldman \& Narayaman, 2004), wherein motor actions can encourage cognitive processing so that later, when the mind is just thinking about the situation, the body is more prepared to execute the learned actions.

These findings suggest that embodied experiences with opportunities for physical interactions with the mediated space may serve as drivers of behavior change. VR simulations can be designed so that users can simulate and practice recommended behaviors in the virtual world to gain the confidence required to carry out the same behaviors in the physical world. Some studies have demonstrated that playing prosocial video games and practicing prosocial behaviors lead to such behaviors in the physical world (Gentile et al., 2009; Greitemeyer \& Osswald, 2010). Exercising in the virtual world has also led to more exercising in the physical world (Fox \& Bailenson, 2009).

Presenting vicarious reinforcement in VR is another effective design approach for behavior change. Observing another person's success or failure is a strong impetus for behavior change (Bandura, 1977). Avatars and agents allow individuals to vividly observe the future consequences of present choices that may be difficult to observe in the physical world. For example, exercising behavior is often difficult to sustain over time due to delayed gratification-exercising, regardless of its intensity, is unable to produce immediately observable changes. In VR, avatars and agents can be designed so that the benefits of exercise are immediately observable through changes in physical appearance (e.g., becoming slimmer with more avatar movements) or the movements of the digital representations (e.g., the avatar is able to move faster and gains more agility). If the user's 
behavior is connected to a clearly observable positive or negative change in his/her avatar, the vicarious reinforcement through the avatar may serve as an impetus for behavior change in the physical world.

Finally, VR provides the capacity for users to implement naturalistic movements when interacting in the mediated environment. Users are able to look around the virtual world as they would the physical world and can reach out to grab objects in a similar way. Scholars have argued that using naturalistic controls to engage with the virtual world creates more complete and accurate mental models than traditional means of interacting with mediated worlds, such as button-presses (Tamborini \& Bowman, 2010). Mental models created from direct experiences are more concrete and detailed than those produced from indirect experiences or descriptions (Hamilton \& Thompson, 2007). Therefore, virtual experiences that closely mimic physical ones are likely to create concrete mental models that are rich in detail. When individuals are later exposed to situations similar to the one they experienced in the virtual world, the mental models are likely to become activated and impact their behaviors. And the more detailed these models are, the more likely they are to direct behavior change (Bandura, 2001; Barsalou, 2009).

\section{Experiencing brands}

VR offers opportunities to provide vivid and engaging brand experiences that take advertising theory and practice above and beyond the traditional delivery of branded messages that typically relies on unidirectional communication with audiences. Embodying a branded experience blurs earlier conceptualizations of the roles of the sender and receiver of the messagebecause the experience is highly interactive, consumers become actively engaged in the persuasion process and even take part in the construction of the message.

So, consider a branded experience from Kia, the automotive manufacturer, which uses VR to deliver a test-drive simulation to potential consumers. Consumers are now able to directly interact with the car without ever stepping inside a dealership, feeling the responsiveness and handling of the vehicle and even the vibration as the tires hit the road. Such branded experiences integrate the self in the mental model of the brand as consumers remember their own arms and hands touching and moving objects in the virtual world, thereby endorsing the brand or product. Self-endorsing, a novel advertising strategy afforded by VR wherein the self is actively integrated 
within a branded experience (Ahn \& Bailenson, 2011), favorably impacts brand preferences. Studies have demonstrated that virtually associating the self and the brand leads to positive attitudes and purchase intentions for the brand, even if the consumer has never seen it before (Ahn \& Bailenson, 2011).

Consequently, interactive design elements that explicitly involve the self within the branded message is more likely to engender favorable brand attitudes than a passive viewing experience. So, consider building in a mirror to allow consumers to view a reflection of their self-avatar as they try out a product in the virtual world. Alternatively, offer a personalized product in the virtual world, engraved with the consumer's name. Better yet, have the consumer experience the benefits of the product during the virtual experience by driving the car, wearing the dress, or sitting on the new sofa. The virtual interaction with the product and brand is likely to form strong associations between the self and the brand that transfer to the physical world.

On the other hand, virtual experiences that are novel and stimulating yet irrelevant to the brand and its image may not be as effective. An earlier study looking at the impact of the thematic relevance of advergames and brand attitudes made a similar point: Advergames should be designed so that the theme and content of the game are related to the sponsoring brand in order to elicit favorable brand attitudes as a result of engaging in game play (Wise, Bollks, Kim, Venkataraman, \& Myer, 2008). Following the same logic, when a virtual experience is novel and exciting but irrelevant to the brand, users are likely to enjoy the simulation, but the enjoyment may not lead to favorable brand outcomes. Regardless of the platform, all communication efforts should aim to be consistent with and relevant to the sponsoring brand and its image.

\section{Limitations of embodied experiences}

In communication scholarship and practice, media platforms that provide a rich array of sensory and content cues (e.g., VR) have been favored over 'leaner' platforms (e.g., text-based), with the anticipation being that richer media will lead to better quality communication. As a result, a high presence has often been considered to be a unilaterally positive outcome of media platforms. In contrast, little effort has been invested in exploring the potentially negative outcomes that may result from sensory saturation or information overload in identifying the boundary conditions of embodied experiences. 
Rather than a general, linear association between presence and performance, the efficiency framework takes on a more nuanced approach to understanding the influence of presence by recognizing that different media are appropriate for different tasks (Walther, 2011). For instance, multichannel platforms such as VR have been shown to be better than mental imagery or the imagination when it comes to adopting the perspective of another person (Ahn et al., 2013). Conversely, earlier work demonstrates that face-to-face or multi-channel interactions do not always outperform mediated, indirect communication with platforms that provide fewer cues (Mühlfelder et al., 1999).

VR may be efficient and effective for inducing presence, engaging the user, and rendering an experience enjoyable (Skalski et al., 2011), but this engagement may distract from the content or information provided, making it potentially less efficient for certain goals such as tending to specific facts or recalling the information presented. This presents an interesting paradox wherein the preferred and enjoyed communication platform may not always be the most efficient for a given task. So, embodied experiences in VR that envelop the user with multiple channels of sensory information may not be an optimal platform for information-dense simulations that are often used in educational contexts. Individuals have limited cognitive resources to allocate in the processing of information delivered via mediated environments (Lang, 200o), and multi-channel stimuli may overload users' cognitive capacities and limit the amount and quality of information decoded, stored, and recalled (Kim \& Biocca, 1997). Complex structural features of a message, such as sound effects and edits, increase the attention paid to process these features and, consequently, few resources are left when it comes to successfully encoding and later recalling the information (Lang, 2000). Indeed, some preliminary studies have demonstrated that presence in VR is associated with reduced cued recall (Ahn, Nowak, \& McGillicuddy, 2017; Bailey et al., 2012).

\section{Conclusion}

With the recent development of stand-alone VR systems and wireless headsets, this technology is poised to continue gaining in popularity and accessibility in the coming years. The affordances of embodied experiences, such as presence and the acceleration of time, espouse unique and unprecedented dynamics between users and system features that encourage attitude and behavior change. Therefore, when properly and carefully 
designed and implemented, the increased use of embodied experiences may be a valuable persuasion tool.

However, embodied experiences may not always lead to desired outcomes and should be designed and implemented after careful consideration of goals and intended as well as unintended consequences. In cases where the goal of the message is high-level information processing and recall, preliminary findings suggest that sensory-rich embodied experiences may deplete valuable cognitive resources and lead to cognitive overload. As a result, it's possible that, although users enjoy the experience of the virtual simulation, they fail to effectively process and retain the information provided. Conversely, in cases where the goal is to engage users and elicit attitude and behavior change through visceral experiences, embodied experiences may be more appropriate than traditional platforms. To enjoy the maximal potential for persuasion offered by embodied experiences in VR, theory-driven designs that carefully take into consideration the constraints of individual differences, situational contexts, and the costs and benefits of implementation are recommended.

Furthermore, the increased availability of VR systems has recently introduced a number of multi-user environments, such as Altspace VR, VR Chat, Rec Room, and High Fidelity. In these environments (i.e., social VR), large numbers of users are able to interact and connect in the same virtual space. Although many of the current embodied experiences offered in VR are solitary, humans are by nature social animals. The future of embodied experiences likely lies in multi-user environments, similar to how video gaming has become a social rather than a solitary activity. As more users gather and interact in these spaces over the years, many affordances of embodied experiences will become reexamined and redefined as virtual worlds gradually evolve into socially networked spaces.

\section{References}

Ahn, S.J. (2015). Incorporating Immersive Virtual Environments in Health Promotion Campaigns: A Construal-Level Theory Approach. Health Communication, 3o(6), 545-556. doi:10.108o/10410236.2013.869650.

\& \& Bailenson, J.N. (2011). Self-Endorsing Versus Other-Endorsing in Virtual Environments: The Effect on Brand Attitude and Purchase Intention. Journal of Advertising, 4o(2), 93-106. https://doi.org/10.2753/JOAoog1-3367400207.

— Bailenson, J.N, \& Park, D. (2014). Short- and Long-Term Effects of Embodied Experiences in Immersive Virtual Environments on Environmental Locus of 
Control and Behavior. Computers in Human Behavior, 39, 235-245. https://doi. org/10.1016/j.chb.2014.07.025.

, Bostick, J., Ogle, E., Nowak, K., McGillicuddy, K., \& Bailenson, J.N. (2016). Experiencing Nature: Embodying Animals in Immersive Virtual Environments Increases Inclusion of Nature in Self and Involvement with Nature. Journal of Computer-Mediated Communication, 21(6), 399-419. https://doi.org/10.1111/jcc4.12173.

_, Fox, J, Dale, K.R., \& Avant, J.A. (2015). Framing Virtual Experiences: Effects on Environmental Efficacy and Behavior Over Time. Communication Research, 42(6), 839-863. https://doi.org/10.1177/oog3650214534973.

, Le, A. M. T., \& Bailenson, J. N. (2013). The Effect of Embodied Experiences on Self-Other Merging, Attitude, and Helping Behavior. Media Psychology, 16(1), 7-38. https://doi.org/10.1080/15213269.2012.755877.

— Nowak, K., \& McGillicuddy, K. (2016). Processing Information as a Body of Coral: The Role of Spatial Presence on Learning in Immersive Virtual Environments. National Communication Association Conference. November 10-13, Philadelphia, PA.

Bailey, J., Bailenson, J.N., Won, A.S., Flora, J., \& Armel, K.C. (2012). Presence and Memory: Immersive Virtual Reality Effects on Cued Recall. Proceedings of the International Society for Presence Research Annual Conference. 24-25 October, Philadelphia, PA. Retrieved 5July 2017 from https://vhil.stanford.edu/mm/2012/ bailey-ispr-presence-memory.pdf.

Bandura, A. (2001). Social Cognitive Theory of Mass Communication. Media Psychology, 3(3), 265-299. https://doi.org/10.1207/S1532785XMEP0303_03

_. (1977). Self-Efficacy: Toward a Unifying Theory of Behavioral Change. Psychological Review, 84

(2), 191-215. https://doi.org/10.1037/0033-295X.84.2.191Barsalou, L.W. (2009). Simulation, situated conceptualization, and prediction. Philosophical Transactions of the Royal Society B, 364, 1281-1289.

Batson, C.D., Polycarpou, M.P., Harmon-Jones, E., Imhoff, H.J., Mitchener, E.C., Bednar, L.L., et al. (1997). Empathy and Attitudes: Can Feeling for a Member of a Stigmatized Group Improve Feelings Toward that Group? Journal of Personality and Social Psychology, 72(1), 105-118. Retrieved 9 March 2018 from https://psycnet. apa.org/buy/1997-02176-oog.

Biocca, F. (1997). The Cyborg's Dilemma: Progressive Embodiment in Virtual Environments. Journal of Computer-Mediated Communication, 3(2). https:// doi.org/10.1111/j.1083-6101.1997.tbooo7o.x.

Blascovich, J. \& Bailenson, J. (2011). Infinite Reality: Avatars, Eternal Life, New Worlds, and the Dawn of the Virtual Revolution. New York, NY: Harper Collins. Evans, S.K., Pearce, K.E., Vitak, J., \& Treem, J.W. (2017). Explicating Affordances: A Conceptual Framework for Understanding Affordances in Communication 
Research. Journal of Computer-Mediated Communication, 22(1), 35-52. https:// doi.org/10.1111/jcc4.12180.

Fazio, R.H., \& Zanna, M.P. (1981). Direct Experience and Attitude-Behavior Consistency. In L. Berkowitz (ed.). Advances in Experimental Social Psychology, 14, 161-202. New York, NY: Academic Press.

Feldman, J., \& Narayanan, S. (2004). Embodied Meaning in a Neural Theory of Language. Brain and Language, 89(2), 385-92. doi: 10.1016/Soo93-934X(03)00355-9. Gentile, D.A., Anderson, C.A., Yukawa, S., Ihori, N., Saleem, M., et al. (2009). The Effects of Prosocial Video Games on Prosocial Behaviors: International Evidence from Correlational, Longitudinal, and Experimental Studies. Personality and Social Psychology Bulletin, 35(6), 752-763. doi: 10.1177/0146167209333045.

Greitemeyer, T. \& Osswald, S. (2010). Effects of Prosocial Video Games on Prosocial Behavior. Journal of Personality and Social Psychology, 35(6), 211-221. 10.1177/0146167209333045.

Hamilton, R.W., \& Thompson, D.V. (2007). Is There a Substitute for Direct Experience? Comparing Consumers' Preferences After Direct and Indirect Product Experiences. Journal of Consumer Research, 34, 546-555. https://doi.org/10.1086/520073.

Hartmann, T., Wirth, W., Vorderer, P., Klimmt, C., Schramm, H., Böcking, S. (2015). Spatial Presence Theory: State of the Art and Challenges Ahead. In Lombard, M., Biocca, F., Freeman, J., IJsselsteijn, W., \& Schaevitz, R. (eds.) Immersed in Media. Cham, Switzerland: Springer International Publishing AG.

Hertwing, R., Barron, G., Weber, E.U., \& Erev, I. (2004). Decisions from Experience and the Effect of Rare Events. Psychological Science, 15, 534-539. https://doi. org/10.1111/j.0956-7976.2004.00715.x.

Kim, T. \& Biocca, F. (1997). Telepresence Via Television: Two Dimensions of Telepresence May Have Different Connections to Memory and Persuasion.Journal of Computer-Mediated Communication, 3 (2). https://doi.org/10.1111/j.1083-6101.1997. tbooo73.x.

Lanier, J., \& Biocca, F. (1992). An Insider's View of the Future of Virtual Reality. Journal of Communication, 42, 150-172. https://doi.org/10.1111/j.1460-2466.1992. tboo816.x.

Lang, A. (2000). The Limited Capacity Model of Mediated Message Processing. Journal of Communication, 5o(1), 46-70. https://doi.org/10.1111/j.146o-2466.2000. tbo2833.x.

Loewenstein, G. (1996). Out of Control: Visceral Influences on Behavior. Organizational Behavior and Human Decision Processes, 65(3), 272-292. https:// doi.org/10.1006/obhd.1996.0028.

Lombard, M., \& Ditton, T. (1997). At the Heart of it All: The Concept of Presence. Journal of Computer-Mediated Communication, 3 (2). https://doi. org/10.1111/j.1083-6101.1997.tbooo72.x. 
— Snyder-Duch, J. (2001). Interactive Advertising and Presence: A Framework. Journal of Interactive Advertising, 1(2), 56-65. https://doi.org/10.1080/152 52019.2001.10722051.

Mühlfelder, M., Klein, U., Simon, S., \& Luczak, H. (1999). Teams Without Trust? Investigations in The Influence of Video-Mediated Communication on the Origin of Trust Among Cooperating Persons. Behavior \& Information Technology, 18(5), 349-36o. https://doi.org/10.1080/014492999118931.

O'Connor, R.E., Yarnal, B., Dow, K., Jocoy, C.L., \& Carbone, G.J. (2005). Feeling at Risk Matters: Water Managers and the Decision to Use Forecasts. Risk Analysis, 25(5), 1265-1275. 10.1111/j.1539-6924.2005.00675.x.

Petty, R.E., \& Cacioppo, J.T. (1979). Issue Involvement Can Increase or Decrease Persuasion by Enhancing Message-Relevant Cognitive Responses. Journal of Personality and Social Psychology, 37, 1915-1926. 10.1037/0022-3514-37.10.1915.

Rajecki, D.W. (1982). Attitudes: Themes and Advances. Sunderland, MA: Sinauer Associates.

Rheingold, H. (1992). Virtual Reality. New York, NY: Simon \& Schuster.

Rizzo, A., Buckwalter, G., Forbell, E., Reist, C., Difede, J., Rothbaum, B.O., Lange, B., Koenig, S., \& Talbot, T. (2013). Virtual Reality Applications to Address The Wounds Of War. Psychiatric Annals, 43(3), 123-138. https://doi. org/10.3928/00485713-20130306-08.

Rosenberg, R.S., Baughman, S.L., \& Bailenson, J.N. (2013). Using Superpowers in Virtual Reality to Encourage Prosocial Behavior. PLoS ONE 8(1): e55003. https:// doi.org/10.1371/journal.pone.0055003.

Schubert, T., \& Crusius, J. (2002). Five Theses on the Book Problem: Presence in Books, Film And VR. In F. R. Gouveia \& F. Biocca (eds.), PRESENCE 2002 - Proceed-

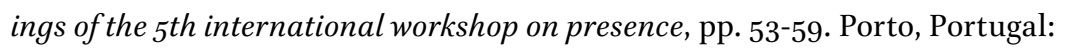
Universidad Fernando Pessoa.

— Friedmann, F., \& Regenbrecht, H. (2001). The Experience of Presence: Factor Analytic Insights. Presence: Teleoperators and Virtual Environments, 1o(3), 266-281. https://doi.org/10.1162/105474601300343603.

Skalski, P., Tamborini, R., Shelton, A., Buncher, M., \& Lindmark, P. (2011). Mapping the Road to Fun: Natural Video Game Controllers, Presence, and Game Enjoyment. New Media \& Society, 13 (2), 224-242. https://doi.org/10.1177/1461444810370949.

Slater, M., \& Wilbur, S. (1997). A framework for immersive virtual environments (FIVE): Speculations on the role of presence in virtual environments. Presence: Teleoperators and Virtual Environments, 6, 603-616.

Stern, P.C. \& Fineberg, H.V. (eds.) (1996). Understanding Risk: Informing Decisions in a Democratic Society. Washington, DC: National Academy Press.

Sutherland, I. (1968). A Head-Mounted Three-Dimensional Display. Proceedings of the AFIPS Fall Joint Computer Conference, 757-764. Washington, D. C.: Thompson Books. 
Tamborini, R., \& Bowman, N.D. (2010). Presence in Video Games. In Campanella, C. \& D. Skalski (eds.), Immersed in Media: Telepresence in Everyday Life, 87-109. London: Routledge.

Tamborini, R. \& Skalski, P. (2006). The Role of Presence in the Experience of Electronic Games. In P. Vorderer and Bryant, J. (eds.), Playing Video Games: Motives, Responses, and Consequences, pp. 263-281. Abingdon: Routledge Taylor \& Francis Group.

Vorderer, P., Klimmt, C., Ritterfeld, U. (2004). Enjoyment: At the Heart of Media Entertainment. Communication Theory, 14(1), 388-408. https://doi. org/10.1111/j.1468-2885.2004.tboo321.x.

Walther, J.B. (2011). Visual Cues in Computer-Mediated Communication: Sometimes Less is More. In Kappas, A., \& Krämer, N.C. (eds.), Face-to-Face Communication over the Internet, pp. 17-38. Cambridge/New York: Cambridge University Press.

Wirth, W., Hartmann, T., Böcking, S., Vorderer, P., Klimmt, C., \& Schramm, H. (2007). A Process Model of the Formation of Spatial Presence Experiences. Media Psychology, 9(3), 493-525. https://doi.org/10.1080/15213260701283079.

Wise, K., Bolls, P.D., Kim, H., Venkataraman, A., \& Moyer, R. (2008). Enjoyment of Advergames and Brand Attitudes. Journal of Interactive Advertising, 9, 27-36. https://doi.org/10.1080/15252019.2008.10722145.

Witmer, B.G., \& Singer, M.J. (1998). Measuring Presence in Virtual Environments: A Presence Questionnaire. Presence: Teleoperators and Virtual Environments, $7(3)$, 225-240. doi:10.1162/105474698565686.

Wu, C., \& Shaffer, D.R. (1987). Susceptibility to Persuasive Appeals as a Function of Source Credibility and Prior Experience with the Attitude Object. Journal of Personality and Social Psychology, 52(4), 677-688. https://doi. org/10.1037/0022-3514.52.4.677.

\section{About the author}

Sun Joo Ahn is founding director of the Games and Virtual Environments Lab in the Grady College of Journalism and Mass Communication at the University of Georgia. Her research examines how social media, video/ internet games, and immersive virtual environments influence user attitudes and behaviors. She is exploring how digital technology can be used to encourage better food choices, more physical activity, and better STEM (science, technology, engineering, and math) learning in children. 
